\title{
CONTRIBUIÇÃO AOS ESTUDOS DO CLIMA URBANO: variação térmica e higrométrica em espaços intra-urbanos
}

\author{
Elis Dener Lima Alves \\ Mestrando do Programa de Pós-Graduação em Física Ambiental (UFMT) \\ Av. Fernando Corrêa da Costa, s/nº, Bloco PG Física Ambiental, CEP: 78.060-900, Cuiabá, MT, Brasil \\ Tel.: (65) 3615-8738 - elisdener@hotmail.com \\ Msc.Valdir Specian \\ Valdir77@hotmail.com
}

\section{RESUMO}

O objetivo deste trabalho foi verificar a existencia de variações térmicas e higrométricas em 4 pontos de coleta na área urbana de Iporá-GO, estes pontos se diferenciavam basicamente no uso e ocupaçãodo solo, foram coletados dados de temperatura do ar e umidade relativa, em três horários, às $9 \mathrm{~h}$ (inicio do aquecimento), às $13 \mathrm{~h}$ ( maior aquecimento) e às $22 \mathrm{~h} 30$ (inicio do resfriamento) em dois períodos, o primeiro foi de 28/04/2008 a 10/05/2008, o segundo foi de 05/07/2008 a 14/07/2008. Foram verificados por meio do satélite GOES 10 e da síntese sinótica mensal os sistemas atmosféricos que atuaram nos dias da coleta de dados. Os resultados mostraram que nos dois períodos ocorreram ilhas de calor e ilhas secas, tanto no ponto 2 como no 3, que correspondem aos locais mais urbanizados. Em maio a maior ilha de calor registrada foi de $2,8^{\circ} \mathrm{C}$ de intensidade, e a maior ilha seca foi de $8 \%$, ambas no dia $02 / 05$ no ponto 3 ás $9 \mathrm{~h}$. Já em julho foi observado que esses fenômenos foram mais intensos, devido a presença de uma massa de ar seco, sendo que no dia $09 / 07$ às $22 \mathrm{~h} 30$ foi verificada uma ilha de calor na magnitude de $3,2^{\circ} \mathrm{C}$ e uma ilha seca de $22 \%$.

Palavras-Chave:Clima urbano, ilha de calor, ilha seca, Iporá.

\begin{abstract}
The objective of this work was to verify the existence of thermal variations and higrometrics in 4 points of collection in the urban area of Iporá-GO, these points if basically differentiated in the alone use and ocupation, had been collected given of temperature of air and relative humidity, in three schedules, to $9 \mathrm{~h}$ (beginning of the heating), to 13h (bigger heating) and to $22 \mathrm{~h} 30$ (beginning of the cooling) in two periods, the first one was from 28/04/2008 to 10/05/2008, as it was from $05 / 07 / 2008$ to $14 / 07 / 2008$. The 10 and of the monthly sinotic synthesis atmospheric systems had been verified by means of satellite GOES that had acted in the days of the collection of data. The results had shown that in the two periods dry islands of heat and islands had occurred, as much in point 2 as in the 3 , that they correspond to the places urbanizados. In May the biggest island of registered heat was of $2,8^{\circ} \mathrm{C}$ of intensity, and the biggest dry island was of $8 \%$, both in day $02 / 05$ in 3 point ace $9 \mathrm{~h}$. Already in July it was observed that these phenomena more intense, had had the presence of a dry air mass, being that in day 09/07 to $22 \mathrm{~h} 30$ was verified an island of heat in the magnitude of $3,2^{\circ} \mathrm{C}$ and a dry island of $22 \%$.
\end{abstract}

Key word: Urban climate, island of heat, dry island, Iporá.

\section{RESUMEN}

El objetivo de este trabajo era verificar que Iporá la existencia de variaciones termales y el higrometrico en 4 puntos de la colección en la zona urbana de, estos puntos si está distinguida básicamente en el uso solo y ocupacion, habían sido recogidos dado de la temperatura del aire y la higrometría, en tres horarios, a 9h (principio de la calefacción), a 13h (una calefacción más grande) y a 22h30 (principio del enfriamiento) en dos períodos, primer era a partir de 28/04/2008 a 10/05/2008, pues era a partir de 05/07/2008 a 14/07/2008. Los 10 y de la síntesis sinotica mensual que los sistemas atmosféricos habían sido verificados por medio del satélite VA eso habían actuado en los días de la recogida de datos. Los resultados habían demostrado que en los dos períodos al secar las islas del calor y las islas habían ocurrido, tanto en el punto 2 como en los 3, que corresponden a los urbanizados de los lugares. En mayo la isla más grande del calor registrado estaba de $2,8^{\circ} \mathrm{C}$ de la intensidad, y la isla seca más grande estaba de el $8 \%$, ambos en el día $02 / 05$ a las $9 \mathrm{~h}$ de 3 puntos. Ya en julio fue observado que estos fenómenos más intensos, habían tenido la presencia de una masa de aire seco, el estar ése en el día $09 / 07$ a $22 \mathrm{~h} 30$ fue verificado una isla del calor en la magnitud de $3,2^{\circ} \mathrm{C}$ y una isla seca de el $22 \%$.

Palabras-Clave: Clima urbano, isla del calor, isla seca, Iporá.

\section{INTRODUÇÃO}

As mudanças climáticas globais vem sendo discutidas no meio acadêmico, científico, e entre a população em geral. No entanto, existem divergências entre pesquisadores, alguns afirmam que essas mudanças no clima da terra faça parte de um ciclo natural, já outros atestam que seriam ocasionadas pela ação antrópica. 
As discussões sobre as mudanças climáticas na escala global são as mais enfatizadas, porém, as mudanças no clima ocorrem mais sensivelmente na escala local.

A cidade é o exemplo mais evidente da modificação do clima local, devido a introdução de formas artificiais, como as edificações, a concentração de equipamentos e pessoas, a impermeabilização do solo, a canalização de córregos, dentre outras (MENDONÇA, 1994). Com isso o ambiente urbano vem apresentando anomalias térmicas, higrométricas e pluviométricas, criando um verdadeiro clima urbano, conforme define Monteiro (1976).

A cidade gera um clima próprio, o clima urbano, que esse é o resultado da interferência de todos os fatores que se processam sobre a camada de limite urbano e que agem no sentido de alterar o clima em escala local. Seus efeitos mais diretos são percebidos pela população através de manifestações capazes de desorganizar a vida da cidade e deteriorar a qualidade de vida de seus habitantes (MONTEIRO, 1976).

As anomalias térmicas, chamadas de ilha de calor, são oriundas da energia líquida proveniente do sistema, na qual nas cidades ela é maior devido ao menor albedo dos materiais urbanos. Já as anomalias higrométricas, conhecidas como ilha seca, são provenientes da falta de arborização e de corpos hídricos no meio urbano.

Existem vários estudos que evidenciam as variações da temperatura e umidade do ar nas cidades, pode-se citar:

Oke (1978) que introduziu importantes conceitos para a análise do clima urbano como o Sky vew factor ( relacionado à cobertura da superfície urbana pelas edificações e vegetação urbana), o efeito-oasis ( frescor derivado de áreas verdes urbanas) e o papel da mistura dos solos na formação da ilha de calor.

Lombardo (1985) que realizou estudo verificando a qualidade ambiental na cidade de São Paulo, mostrando a influência da ação antrópica no ambiente, e analisando as conseqüências dessa ação como o fenômeno de ilhas de calor, foi um trabalho pioneiro na utilização de imagens de satélite no estudo do clima urbano.

Danni (1987) constatou que as condições atmosféricas correspondente ao mês de janeiro de 1982 em Porto Alegre exibiram uma distribuição de temperatura que veio a caracterizar o fenômeno ilha de calor, com nítidos contrastes térmicos entre os espaços com ocupação urbana e aqueles residenciais de periferia, bem como a existência de ilhas de frescor.

Sette (1996) que contribuiu para o conhecimento do clima regional de Mato Grosso, principalmente no que se refere aos processos genéticos da pluviosidade nos climas Tropicais Alternadamente Úmido e Seco, também para a caracterização do clima local de Rondonópolis, fornecendo subsídios às pesquisas voltadas à análise ambiental.

Amorim (2000) que explicitou como os diferentes condicionantes geoecológicos e urbanos respondem à atuação dos sistemas atmosféricos, e os tipos de tempo responsáveis pelas maiores ou menores magnitudes dos fenômenos conhecidos como ilhas de calor e ilhas de frescor, assim como as ilhas secas e úmidas.

Viana (2006) investigou as características da temperatura e umidade relativa do ar nos espaços intra-urbanos e rural em Teodoro Sampaio-SP, os horários estabelecidos para as coletas de dados foram às $7 \mathrm{~h}, 9 \mathrm{~h}, 15 \mathrm{~h}$ e $21 \mathrm{~h}$, também foi utilizado um transecto móvel acoplado num veículo automotor, essas coletas ocorreram em janeiro e junho de 2005 (verão e inverno), os seus resultados revelaram ilha de energia térmica na magnitude de $4^{\circ} \mathrm{C}$ às $21 \mathrm{~h} 00 \mathrm{~min}$.

Leão (2008) estudou o comportamento do campo térmico urbano da cidade de Sete LagoasMG nos períodos de agosto e novembro de 2007, a partir de dados climáticos coletados na Estação Climatológica do Instituto Nacional de Meteorologia (INMET) e em experimentos de campo. A análise envolveu a relação entre os elementos climáticos e a tipologia de uso e ocupação do solo. Os dados quando comparados aos da Estação Climatológica, e os dados coletados em campo apresentaram diferenças significativas, constatando-se, portanto, a influência do uso urbano do solo no desempenho térmico da atmosfera local. 
Os estudos acima citados se referem na maioria aos grandes centros urbanos, porém, nas regiões e/ou ambientes mais afastados dos grandes centros de pesquisa o conhecimento sobre o espaço nessa temática é escasso, por isso se faz importante um estudo em cidades pequenas distantes das metrópoles.

As cidades de porte médio e pequeno possuem então características geográficas bastante diferenciadas daquelas de grande porte e metropolitanas e apresentam, portanto, consideráveis facilidades para a identificação de suas paisagens intra-urbana; estas, previamente identificadas, permitirão uma melhor compreensão da interação sociedade-natureza na construção do clima urbano (MENDONÇA, 2003, p. 96).

\section{MATERIAIS E MÉTODOS}

\section{Caracterização do município de Iporá-GO}

O município de Iporá localiza-se na região Sudoeste do Estado de Goiás, nas coordenadas de $16^{\circ} 26^{\prime} 31^{\prime \prime}$ de latitude Sul e 5107’04” de longitude Oeste (Figura 1).

No município de Iporá passam dois rios, o rio Claro e o Caiapó, os ribeirões Santa Marta e Santo Antônio e vários córregos, com destaque para o córrego Tamanduá, que corta a área urbana ao meio, tendo um trecho represado na zona urbana, que forma o lago Pôr do Sol.

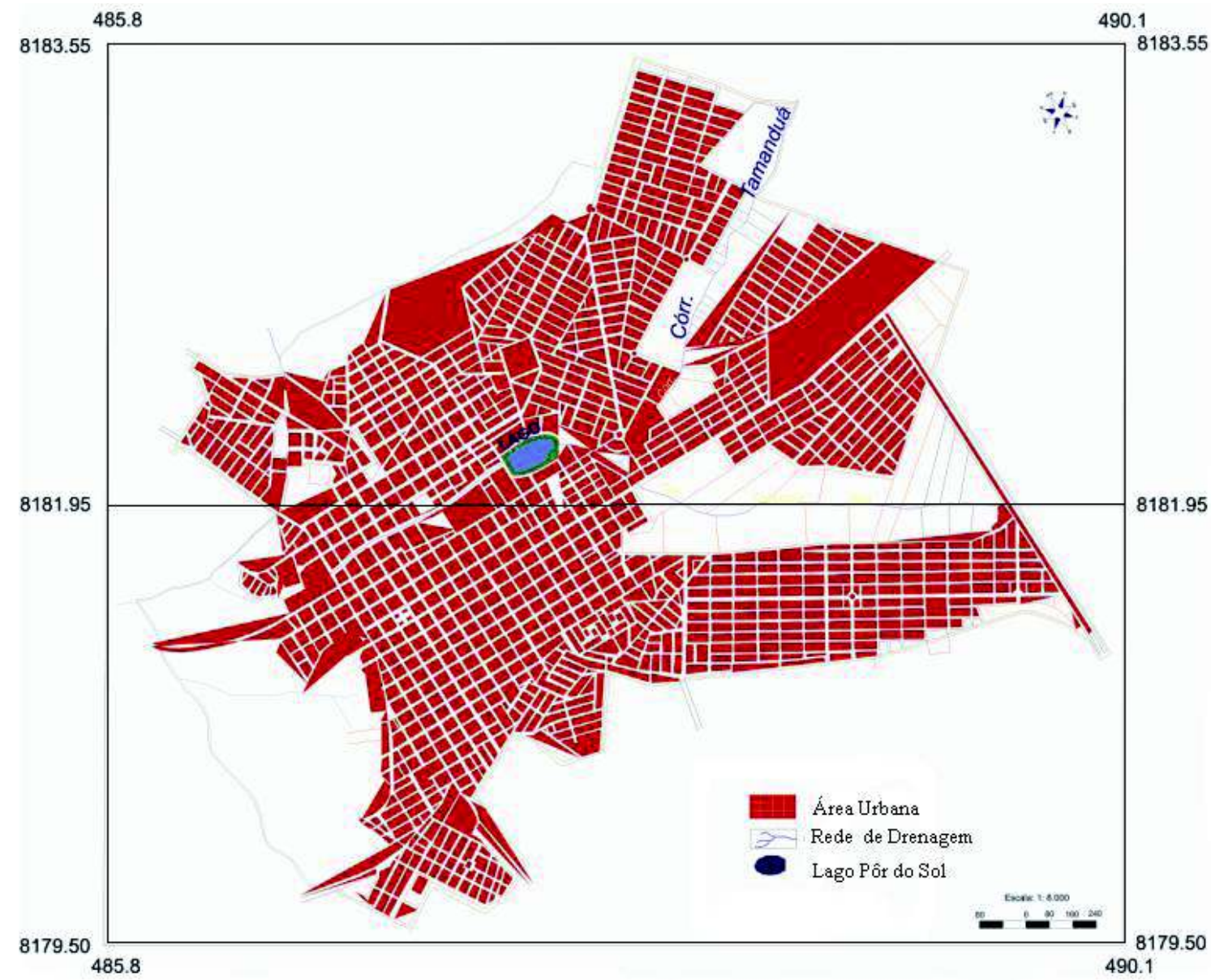

Figura 1 - Mapa de Localização de Iporá.

A parte mais antiga (Centro e Bairro Mato Grosso) da cidade apresenta avenidas largas - com duas pistas e canteiros centrais, algumas mais arborizadas e outras não, as avenidas são cortadas por ruas em pistas simples, será ao longo de uma destas avenidas que será realizada a pesquisa. Todas 
as vias do setor em pesquisa são pavimentadas - asfalto, o centro é menos arborizado e apresenta maior concentração de edificações.

O clima de Iporá de acordo com a classificação de Koopen se enquadra como sendo Tropical Semi-Úmido. Já o sistema classificador de Thornthwaite utilizado por Alves \& Specian (2008) indica que o clima de Iporá é Primeiro Úmido com moderado déficit de água no inverno e grande excesso no verão (B1WW2), apresentando uma pluviosidade média anual de $1617 \mathrm{~mm}$.

As características climáticas de Iporá são típicas do ambiente de cerrado. Pois segundo Nimer (1989) a região dos cerrados tem um elevado índice de precipitação, predominando valores anuais médios entre 1.000 e $2.000 \mathrm{~mm}$, porém mal distribuídos no tempo.

\section{MATERIAIS}

Foram utilizados nesta pesquisa: 4 Termohigrômetros digitais - HT-200 (figura 2); Programa Excel; Programa Surfer 8.0; Imagens do Satélite GOES; Mapa da área urbana de Iporá.

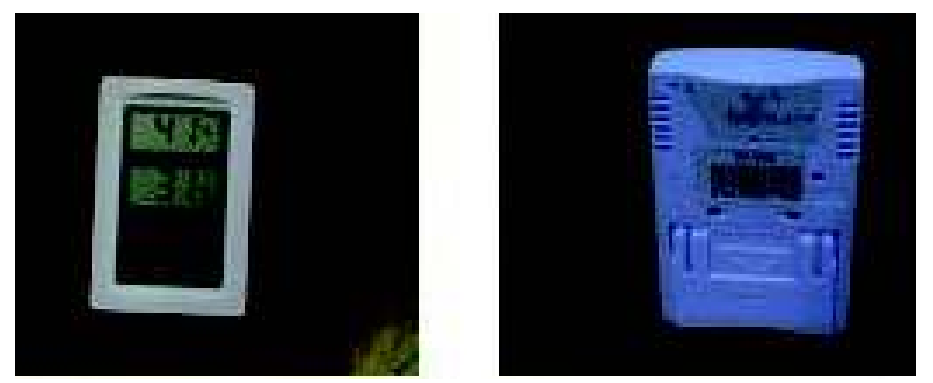

Figura 2 - Fotos dos Termohigrômetros digitais (HT-200).

\section{MÉTODO}

Para o estudo do clima urbano da cidade de Iporá-GO, seguindo a proposta de "adentrar a cidade para tomar-lhe a temperatura" Monteiro (1990), foram escolhidos 4 pontos de coleta de dados que se diferenciavam basicamente pelo uso e ocupação do solo, estes pontos foram distribuídos da periferia ao centro da cidade. No qual:

Ponto 1 (P1). Está localizado na Latitude $16^{\circ} 26^{\prime} 834$ Sul e na Longitude $51^{\circ} 07^{\prime} 251$ Oeste, sua altitude é de $587 \mathrm{~m}$, entre os pontos é o que está mais elevado, a sua área é arborizada, e está próxima a Câmara Municipal de Iporá. A área é toda pavimentada, o espaço é aberto e pouco ocupado (Figura 3A).

Ponto 2 (P2). Está localizado na Latitude $16^{\circ} 26^{\prime} 603$ Sul e na Longitude 510 $07^{\prime} 222$ Oeste, sua altitude é de $584 \mathrm{~m}$. Área central da cidade, região mais movimentada do centro de Iporá. A arborização é composta por árvores de porte baixo, junto a ilha central da pista (Av. Goiás). Nas calçadas dos dois lados não existe arborização e toda área é pavimentada, inclusive as ilhas (Figura 3B).

Ponto 3 (P3). Localiza-se na Latitude 16 $26^{\prime} 263$ Sul e na Longitude 51 $06^{\prime} 869$ Oeste, sua altitude é de $582 \mathrm{~m}$, está na Avenida Goiás. É o ponto que apresenta maior espaço livre, sem barreiras para a circulação do ar. Um fator de caracterização importante para o ponto é a proximidade da feira coberta de Iporá, com telhado de zinco. Na calçada não existe arborização e a área é toda pavimentada (Figura 3C).

Ponto 4 (P4). Está localizado na Latitude $16^{\circ} 25^{\prime} 914$ Sul e na Longitude $51^{\circ} 06^{\prime} 579$ Oeste, sua altitude é de $569 \mathrm{~m}$, entre os pontos é o de menor altitude. A principal característica do mesmo é a proximidade com o lago Pôr do Sol, está no outro extremo da cidade (periferia) em relação ao ponto 1. Todos os terrenos são ocupados, e existe neste ponto uma chácara (Figura 3D). 


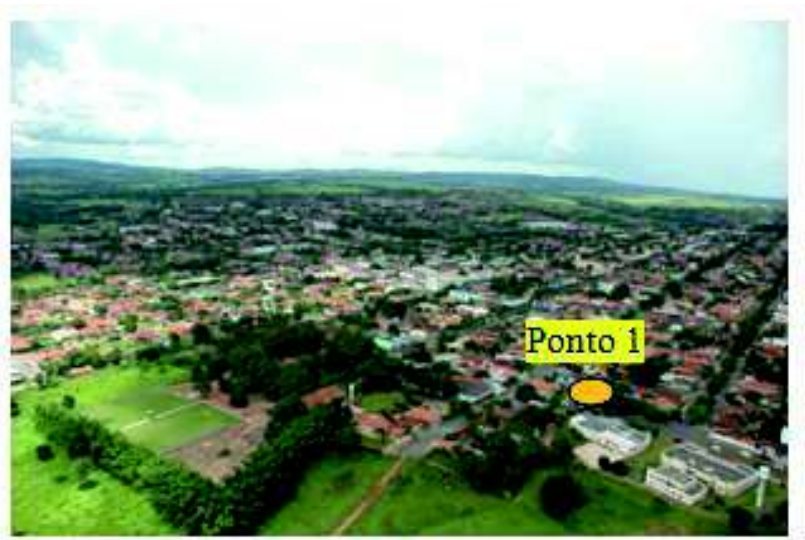

A

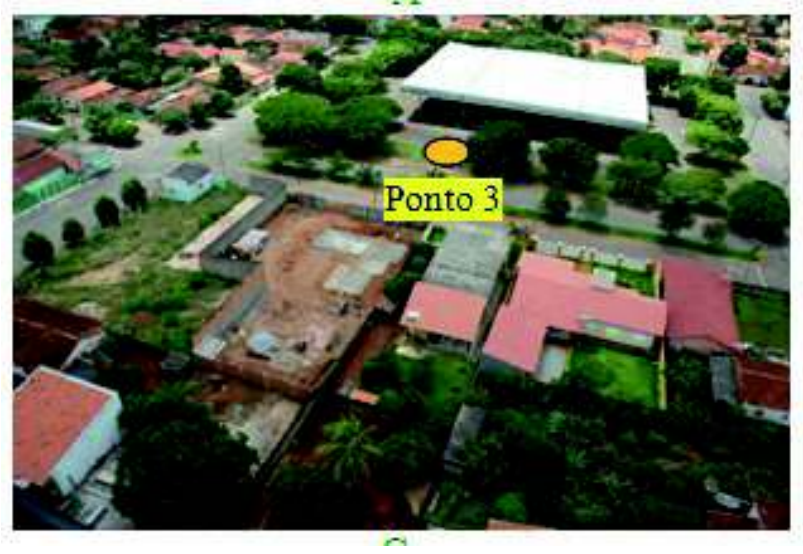

Figura 3 - Localização dos pontos de coleta

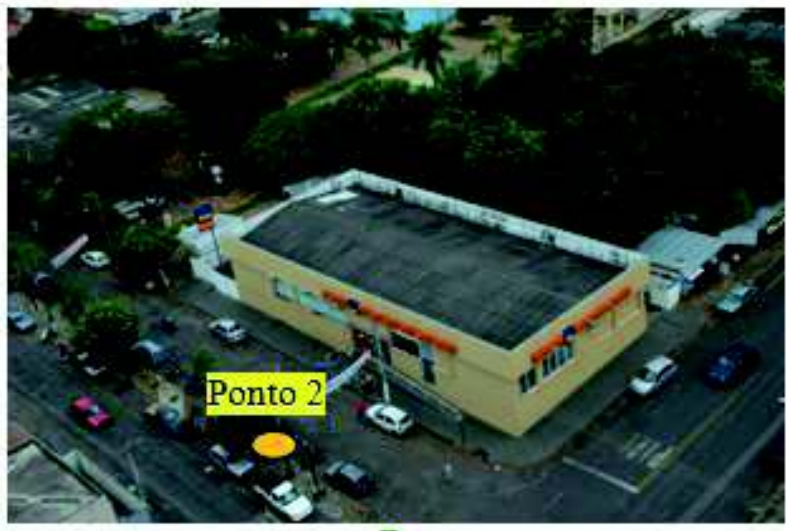

B

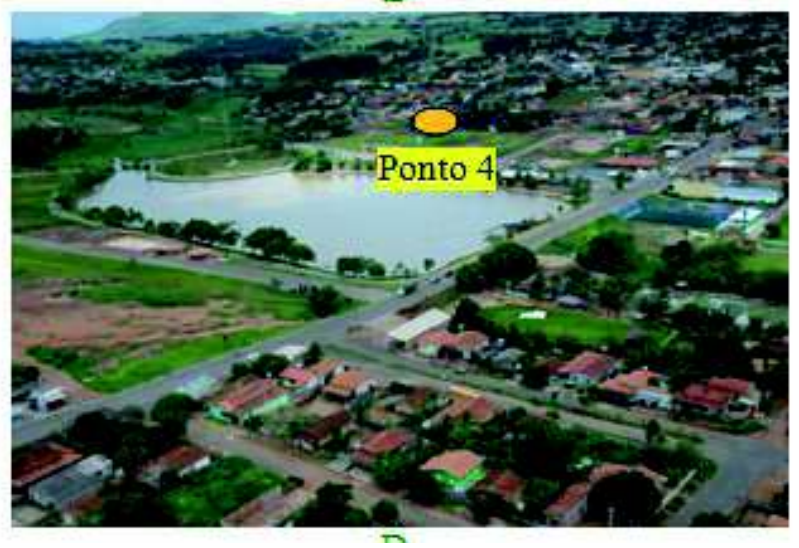

$\mathrm{D}$

As coletas de dados (temperatura do ar e umidade relativa) foram realizadas em dois períodos, no final de abril e inicio de maio (28/04 a 10/05 de 2008), e em julho (05/07 a 14/07 de 2008), em três horários, às $9 \mathrm{~h} 00 \mathrm{~min}, 13 \mathrm{~h} 00 \mathrm{~min}$ e $22 \mathrm{~h} 30 \mathrm{~min}$, estes horários foram escolhidos porque estes representam, respectivamente, três períodos distintos, manhã (início do aquecimento), tarde (maior aquecimento), e noite (início do resfriamento).

Após a coleta de dados foram confeccionados gráficos no programa Excel ${ }^{\circledR}$, e mapas de isotermas e isoígras no programa Surfer ${ }^{\circledR}$ 8.0, foram também verificadas as imagens do satélite GOES disponíveis no sítio do Centro de Previsão do Tempo e Estudos Climáticos (CPTEC), nas quais foram utilizadas para a identificação dos sistemas atmosféricos regionais e dos seus respectivos centros de atuação.

\section{RESULTADOS E DISCUSSÕES}

\section{$1^{\circ}$ Período de coleta (28/04/08 - 10/05/08)}

\section{Condiçoes sinóticas}

As condições sinóticas descritas no $1^{\circ}$ e $2^{\circ}$ período de coletas se baseiam nas informações obtidas através da análise sinótica disponibilizada pelo sítio do CPTEC/INPE associadas às imagens do Satélite GOES 10 (figura 04).

De acordo com a análise sinótica a nona frente fria do mês de abril foi um dos sistemas frontais mais intensos deste mês. Ela veio do sul do continente, passou por Bahia Blanca (Argentina) durante o dia 28 e chegou a Rio de Janeiro no dia 30 (figura 4A). Este sistema frontal também avançou pelo interior do continente e em seu percurso provocou fortes quedas nas temperaturas no Centro-Sul e no sul da Região Norte.

Mercator - volume 8, número 17, 2009: set./dez. 
A primeira frente fria do mês de maio foi originada de um ciclone extratropical sobre o RS no dia 02/05 (figura 4B). O sistema frontal reforçou o ar frio que já atuava no interior do país no final do mês anterior e o ciclone extratropical foi responsável pela chuva e vento forte no RS e SC nos primeiros 4 dias do mês.

O ramo frio deste sistema frontal atuou primeiramente no interior do continente, deslocandose entre PR e sul do AC no dia 2. Entre os dias 3 e 4 (figura 4D e 4E) esta frente fria deslocou-se pelo Estado de SP, tanto pelo interior quanto pelo litoral, e chegou até a capital Fluminense, mas perdendo suas características de frente fria.

Apesar do sistema frontal, já bem enfraquecido, a massa de ar frio e seco na retaguarda do sistema permaneceu forte e manteve as temperaturas baixas durante a madrugada nos Estados da Região Sul, em SP e sul de MS. A frente fria chegou ao sul da BA (Ilhéus) no dia 07 (figura 4F), e a partir daí, o sistema adquiriu características subtropicais, deslocando-se pelo oceano. O terceiro sistema frontal deslocou-se pela Argentina a partir do dia 07 e chegou, pelo litoral, até o Estado do Rio de Janeiro no dia 10 (figura $4 \mathrm{G}$ e $4 \mathrm{H}$ ).
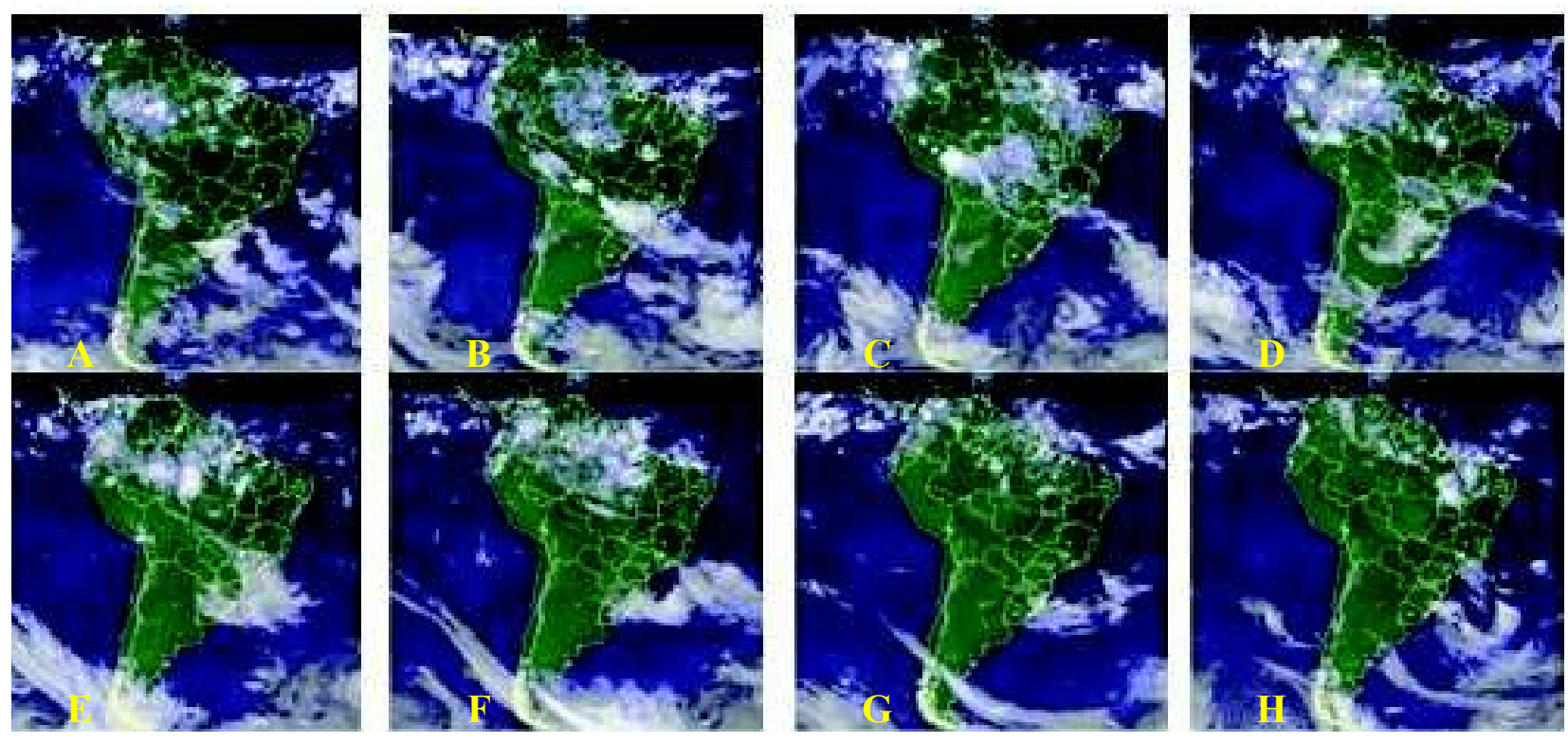

Figura 4 - Imagens do satélite GOES $\left(1^{\circ}\right.$ período).

\section{VARIAÇÃO DA TEMPERATURA E DA UMIDADE}

Durante este período a temperatura não esteve muito elevada, já a umidade apresentou índices medianos, não houve grandes flutuações termohigrométricas entre os pontos de coleta, a não ser no dia $02 / 05$.

Conforme mostra a figura 05, até o dia 30/04 a temperatura e a umidade variaram apenas diurnamente, porém com a chegada de um sistema frontal no dia 02/05 houve um aumento significativo da temperatura e uma queda da umidade, este fato interessante ocorreu porque esse sistema frontal que chegou em Goiás já estava enfraquecido, e o contato desse sistema com a superfície provocou inicialmente um aumento da temperatura.

Com o avanço desse sistema as temperaturas foram gradativamente diminuindo, tendo sua mínima às $9 \mathrm{~h}$ do dia $04 / 05$, a umidade foi aumentando e teve sua máxima tambem às $9 \mathrm{~h}$.

A partir do dia 05/05 com a saída desse sistema frontal a temperatura e a umidade se comportaram normalmente, baixa temperatura às $9 \mathrm{~h}$ e às $22 \mathrm{~h} 30$, e temperatura elevada às $13 \mathrm{~h}$, alta umidade às $9 \mathrm{~h}$ e as $22 \mathrm{~h} 30$, e baixa às $22 \mathrm{~h} 30$.

A figura 5 mostra também as variações da temperatura e da umidade entre os pontos de coleta, sendo que o P1 e o P4 apresentaram em todo o período temperaturas mais baixas e umidades mais 
elevadas que os pontos 3 e 4, essas diferenças foram ocasionadas devido ao uso e ocupação do solo descritos no método.

Temperatura e Umidade do Ar na área urbana de Iporá-GO (28/04/08 - 10/05/08)

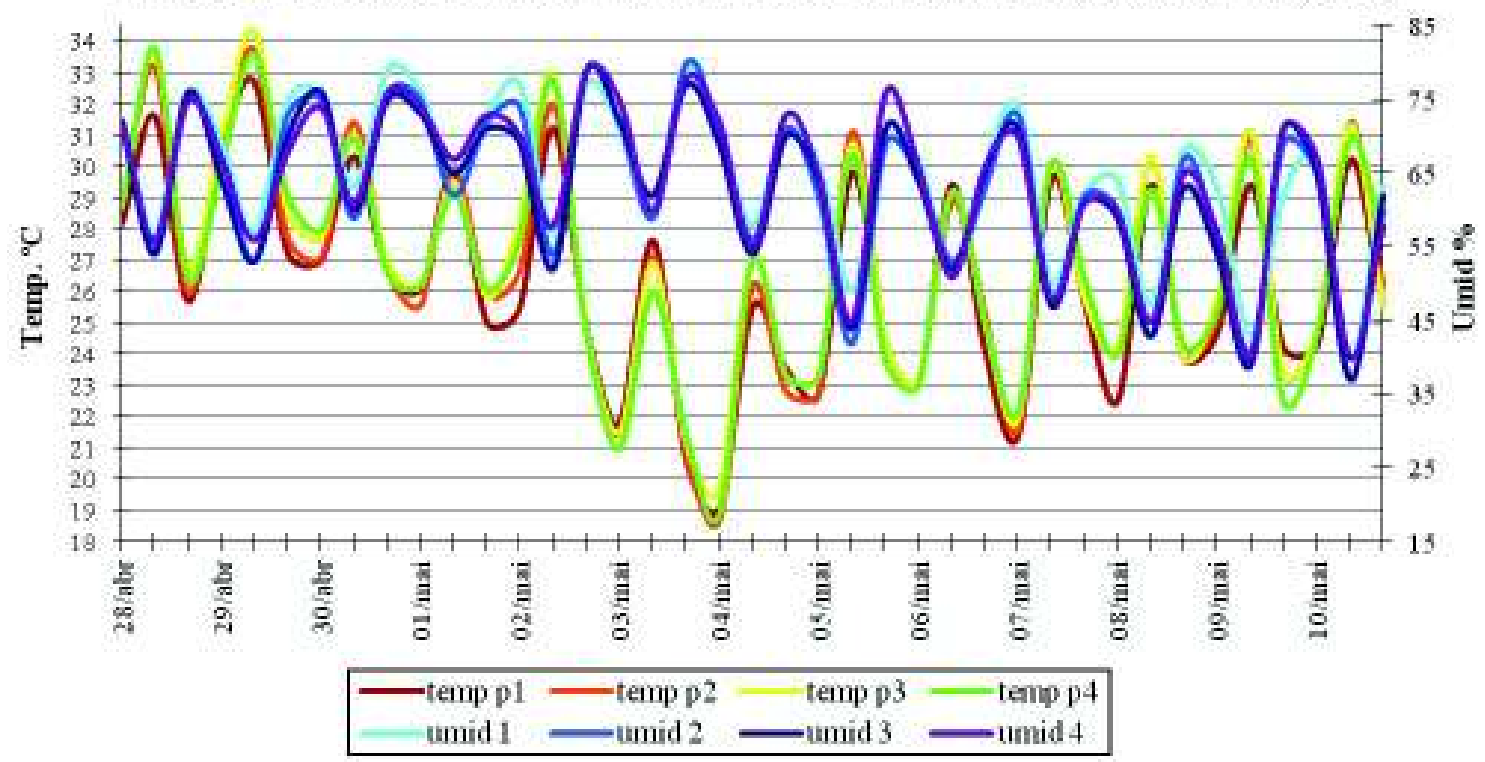

Figura 5 - Variação da temperatura e umidade nos pontos de coleta no mês de maio.

Durante este período foi observado algumas ilhas de calor e ilhas secas, que persistiam a aparecer no $\mathrm{P} 3$, o caso mais representativo ocorreu no dia $02 / 05$ às $9 \mathrm{~h}$, apresentando concomitantemente uma ilha de calor e uma ilha seca na magnitude de $2,8^{\circ} \mathrm{C}$ e $8 \%$ (figura 6).

Pode-se notar na espacialização da ilha de calor, que a temperatura mais baixa ocoreu no P1 e esta foi aumentando a medida que se aproximava do P3, já na espacialização da ilha seca a umidade mais elevada foi verificada no P1 e foi decrescendo em direção ao ponto 3.
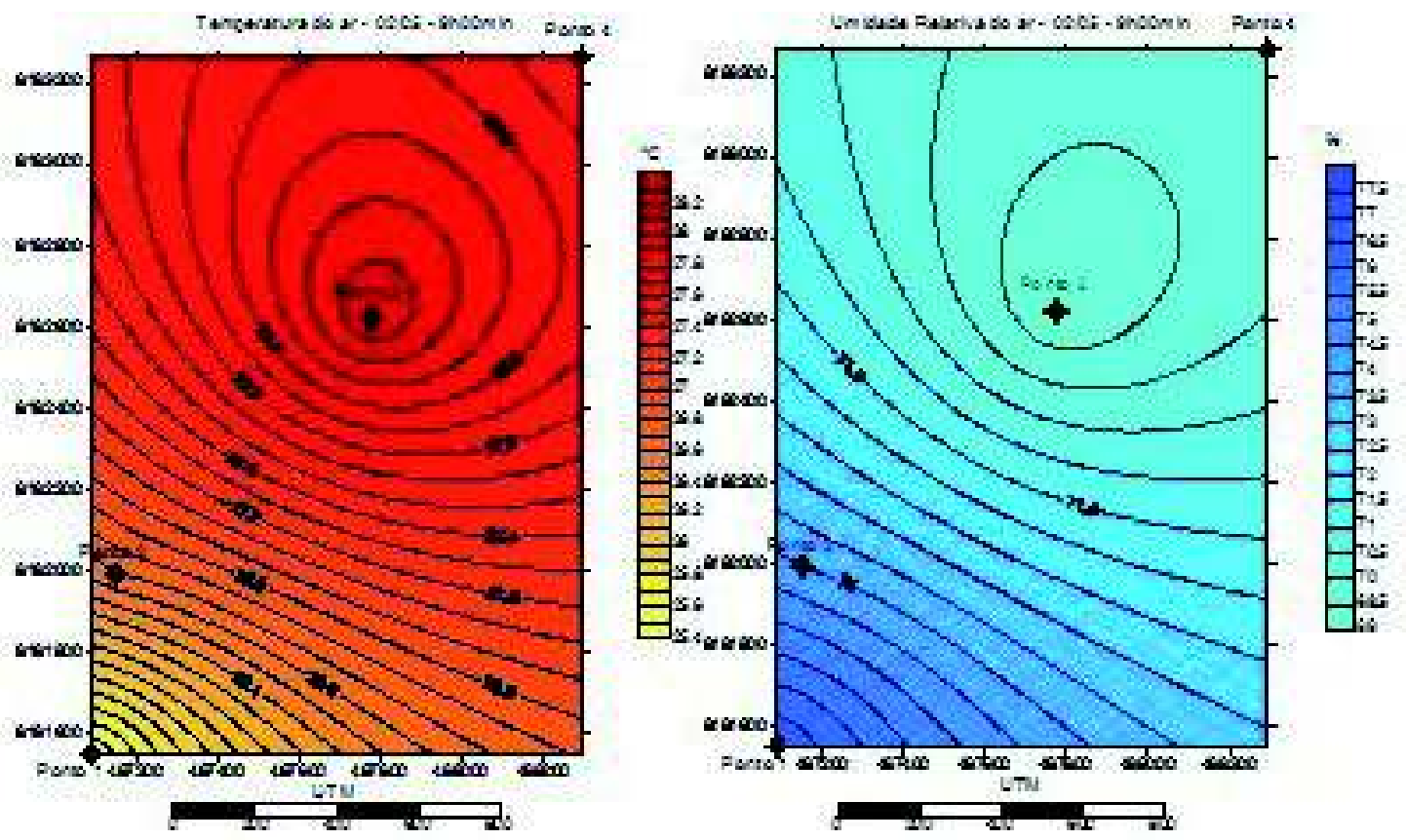

Figura 6 - Isotermas e isoígras do dia 02/05/08. 


\section{Condições sinóticas}

De acordo com a análise sinótica a primeira frente fria que atuou em latitudes a norte de 40S, teve origem de uma frontogênese que ocorreu sobre a Patagônia no dia 29 (figura 7A) do mês anterior.

No dia 1 (figura 7B) a frente fria associada a este sistema deslocou-se pela Província de Buenos Aires. Este sistema deslocou-se até o leste de Santa Catarina no dia 03 (figura 7C e 7D). Em sua trajetória causou convecção de forma localizada principalmente entre noroeste do Uruguai, oeste, centro e nordeste do RS.

Até o dia 10 mais dois sistemas frontais atuaram no continente, entre a Província de Buenos Aires e o Rio Grande do Sul: um durante o dia 06 (segunda frente fria) e o outro entre os dias 07 e 08 (terceira frente fria, figura 7E e 7F). O quarto sistema frontal atuou rapidamente pela faixa leste da Província de Buenos Aires, entre os dias 8 e 10 (figura 7G e 7H), passando entre Bahia Blanca e Montevidéu, sendo que esses sistemas não estavam influenciando no tempo no estado de Goiás, pois neste havia o predomínio de uma massa de ar seco, a figura 7 mostra a evolução desses sistemas descritos anteriormente.
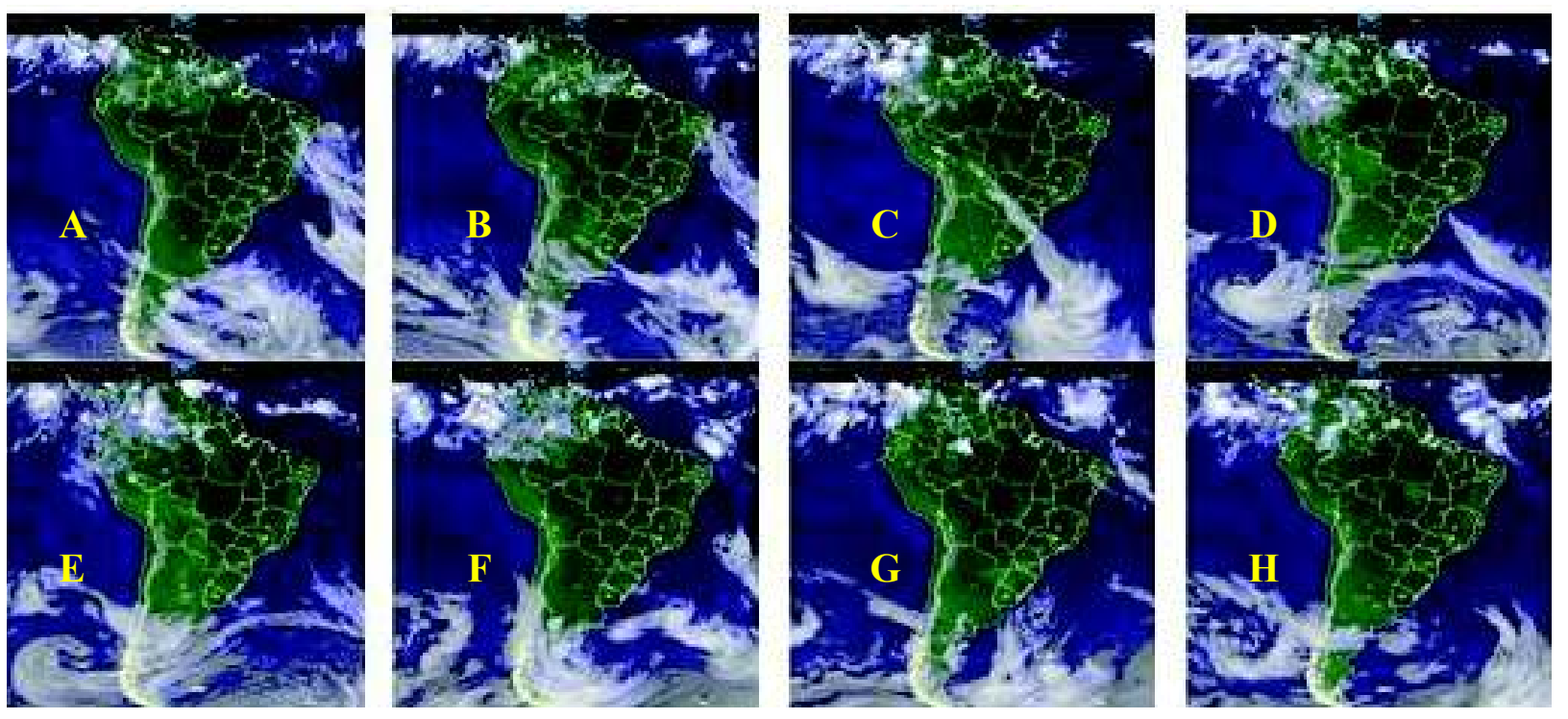

Figura 7 - Imagens do satélite GOES ( $2^{\circ}$ período).

\section{VARIAÇÃO DA TEMPERATURA E DA UMIDADE}

Neste período a umidade relativa do ar esteve bem abaixo das taxas encontradas em maio, não houve a entrada de frentes frias em Goiás. O sistema atmosférico atuante neste período foi uma massa de ar seco, o que não ocasionou grandes variações no comportamento térmico durante o período.

No entanto, as flutuações na temperatura e na umidade entre os pontos de coleta foi elevada, se comparadas aos dados do primeiro período.

Por exemplo, a umidade no ponto 4 esteve superior a dos outros pontos em todo o período, apresentando um elevado gradiente, sendo que os pontos 2 e 3 apresentaram as menores taxas de umidade no período da manhã (9h), confirmando o que foi verificado no ponto 2 e $3 \mathrm{em}$ maio.

Já no período da tarde (13h) as menores taxas higrométricas foram observadas no ponto 1 e no ponto 4 . Já no ponto 2 e 3 as baixas umidades estiveram relacionadas à manhã e a noite (figura 8). 
Temperatura e Umidade do Ar na área urbana de Iporá-GO (05/07/08 - 14/07/08)

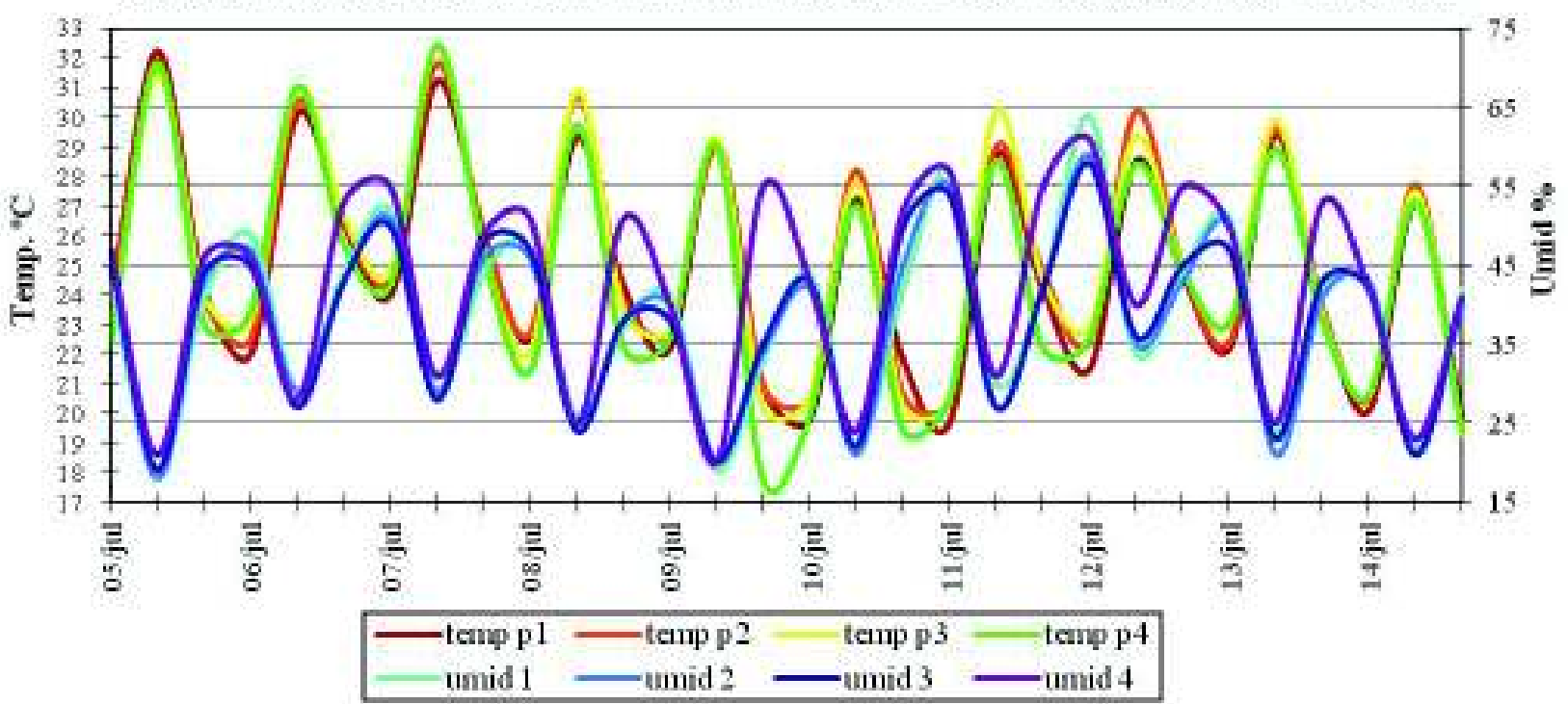

Figura 8 - Variação da temperatura e umidade nos pontos de coleta no mês de julho.

A figura 9 mostra uma ilha de calor englobando o ponto 1 e o 2 , com a intensidade de $3,2^{\circ} \mathrm{C}$, assim como uma ilha de frescor no $\mathrm{P} 4$ com a mesma intensidade, uma ilha úmida no $\mathrm{P} 4$ na magnitude de 22\%, e uma ilha seca de mesma intensidade englobando o P1 e o P2 no horário das $22 \mathrm{~h} 30$.
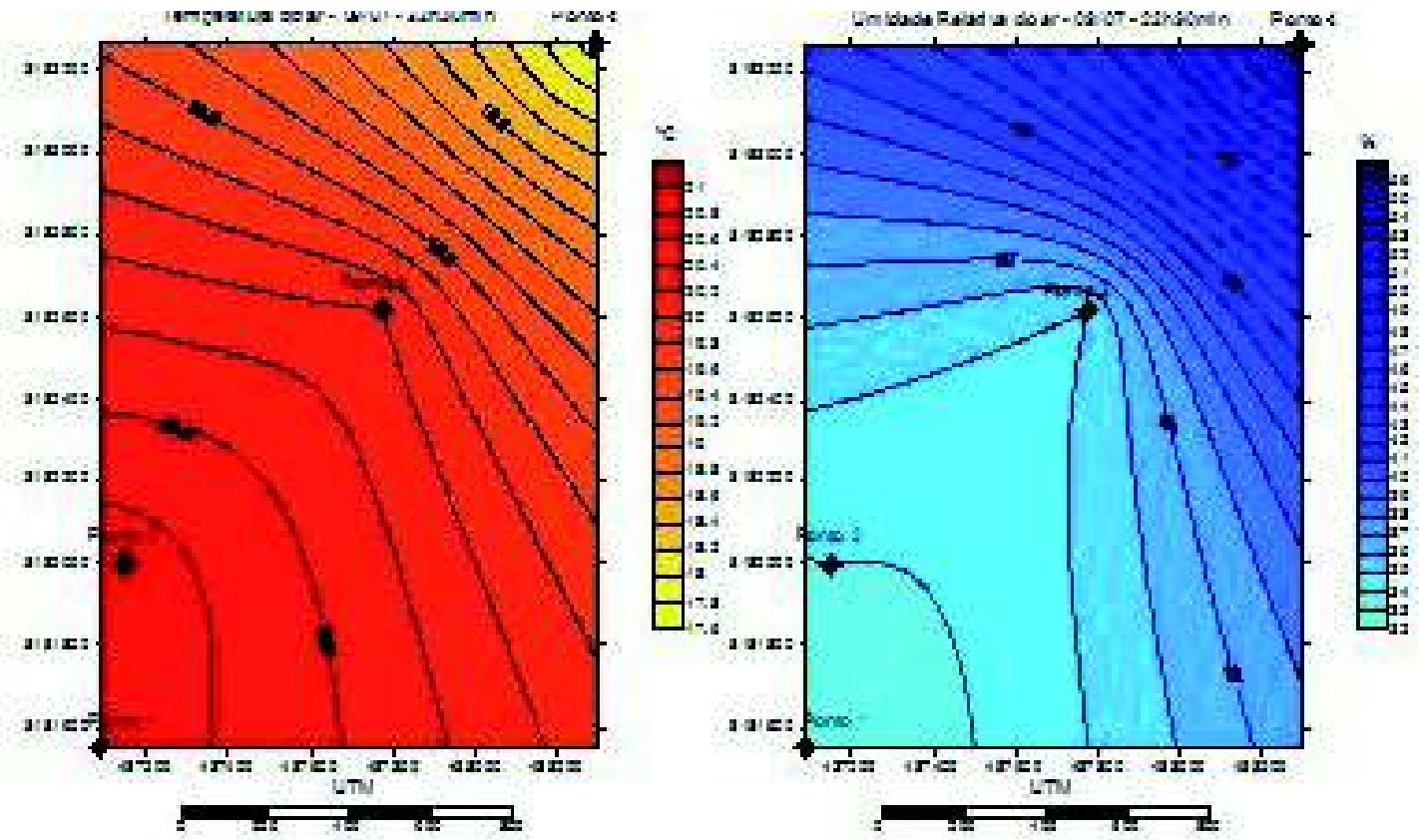

Figura 9 - Espacialização da temperatura e umidade no dia 09/07/08.

Na figura 10 tem-se o comportamento da temperatura nos 4 pontos nos 10 primeiros dias de coleta em maio e em julho, nela pode-se observar que não houve grande diferença térmica entre os dois períodos de coleta. 


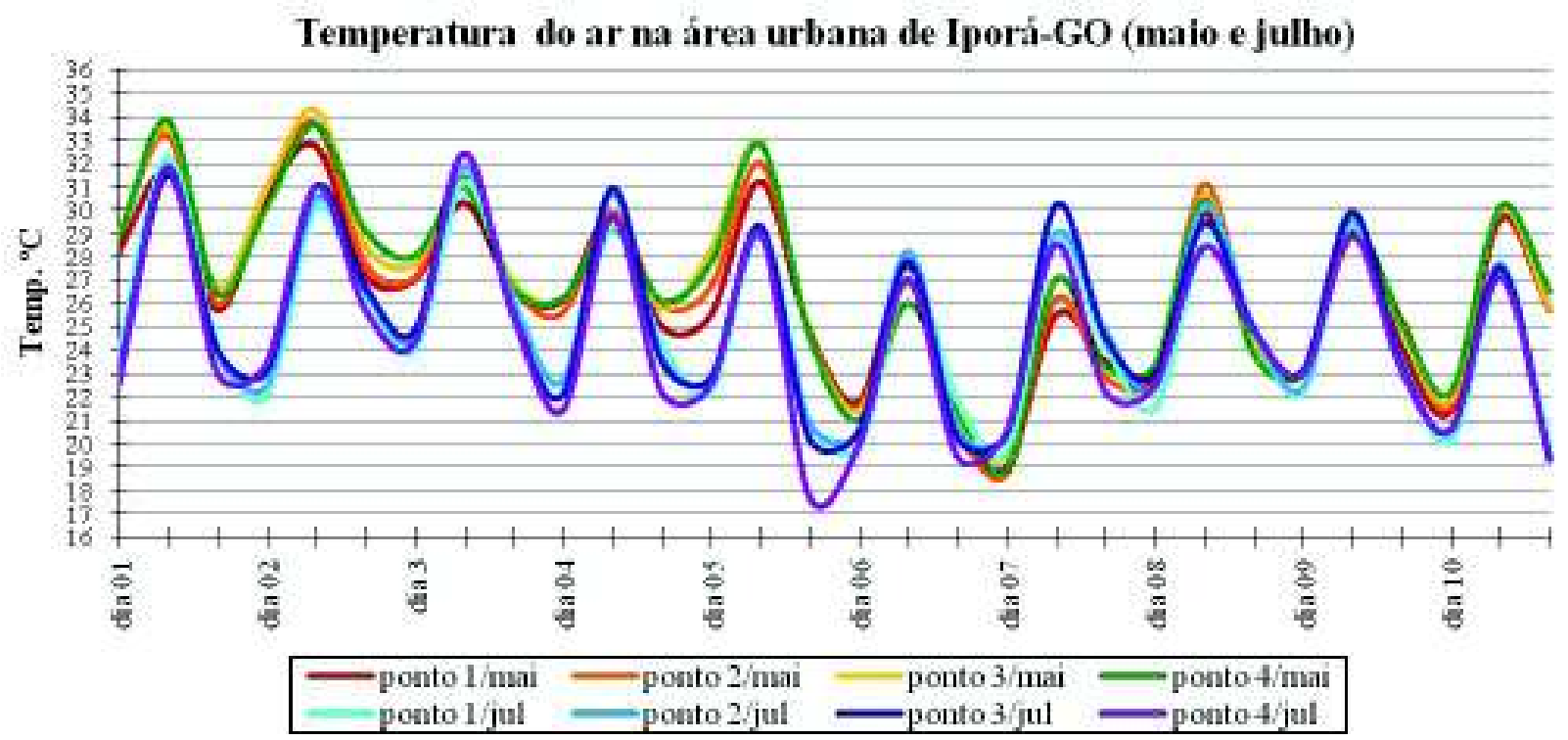

Figura 10 - Variação da temperatura nos dois períodos de coleta ( maio e julho).

Na figura 11 observa-se que a umidade nos 4 pontos nos 10 primeiros dias de julho estiveram inferiores em relação a maio, devido aos sistemas atmosféricos que atuaram nesses períodos, maio (frente fria predominantemente), julho (massa de ar seco).

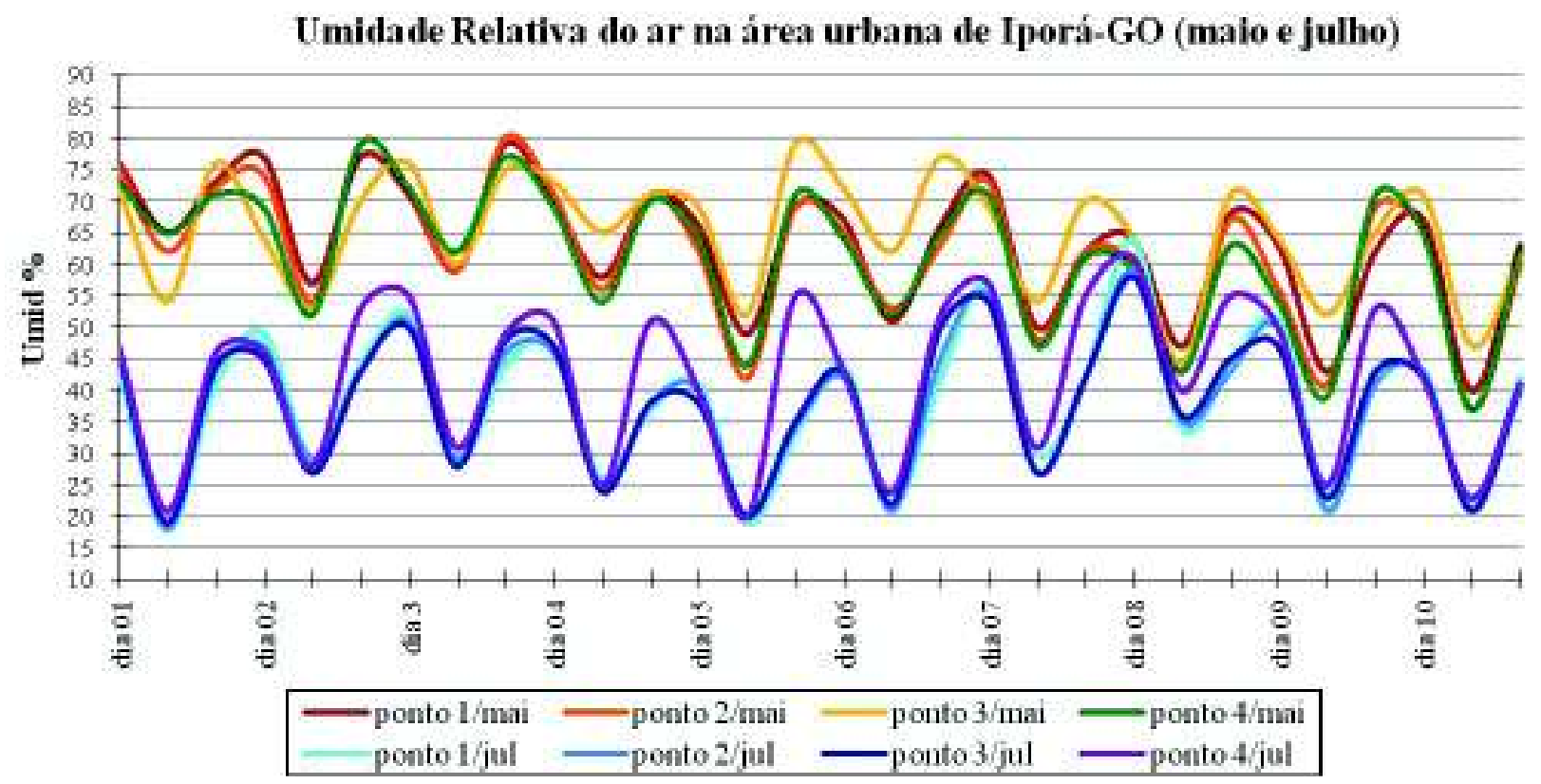

Figura 11 - Variação da umidade nos dois períodos de coleta ( maio e julho).

\section{CONSIDERAÇÕES FINAIS}

Neste estudo foi possivel observar que, independentemente do período de coleta, os pontos localizados nas áreas mais urbanizadas (P2 e P3) apresentaram temperaturas mais elevadas, configurando nestes locais ilhas de calor.

Porém, em estudos futuros se recomenda a coleta de dados em períodos mais distintos, como verão e inverno, pois acredita-se que dessa forma se possa evidenciar mais claramente as distintas magnitudes das anomalias termohigrométricas.

Mesmo assim, foi verificado que em julho na atuação de uma massa de ar seco, as ilhas de calor foram mais intensas, assim como as ilhas secas, este fato se explica pelo céu claro e a baixa 
velocidade do vento tipicos desse sistema atmosférico, que faz com que a radiação global seja maior e que haja pouco transporte dessa energia.

Um fator importante a se dizer é que neste estudo não se coletou dados em nenhum ponto da área rural, e de acordo com alguns autores quando se compara a temperatura urbana com a rural a intensidade das ilhas de calor tendem a ser maiores.

\section{REFERÊNCIA BIBLIOGRÁFICA}

ALVES, E. D. L.; SPECIAN, V. Caracterização do Balanço Hídrico e Clima do Município de Iporá (GO). In: $1^{\circ}$ Encontro de Divulgação da Produção Científica do Oeste de Goiás. 2008. p. 1 - 22. Disponível em meio digital (CD Room).

AMORIM, M. C. de C. T. O clima urbano de Presidente Prudente/SP. 2000. Tese (Doutorado) - Programa de Pós-Graduação em Geografia Física, Faculdade de Filosofia, Letras e Ciências Humanas, Universidade de São Paulo, São Paulo, 2000.

DANNI, I. M. Aspectos têmporo - espaciais da temperatura e umidade relativa de Porto Alegre em Janeiro de 1982 - contribuição ao estudo do clima urbano. 1987. Dissertação (Mestrado) - Programa de Pós-Graduação em Geografia Física, Faculdade de Filosofia, Letras e Ciências Humanas, Universidade de São Paulo, São Paulo, 1987.

IMAGENS DO SATÉLITE GOES - Disponível em < http://www.cptec.inpe.br > . Acesso em Agosto 2008. LEÃO, M. S. Diagnóstico climático e estudo das variações termo-higrométricas do município de Sete Lagoas - MG. 2008. 150 p. Dissertação (Mestrado em Geografia), Programa de Pós-Graduação em Geografia, Universidade Federal de Minas Gerais, Minas Gerais, 2008.

LOMBARDO, M. A. Ilha de Calor nas Metrópoles. São Paulo: Hucitec, 1985, p. 244.

MENDONÇA, F. de A. O Clima e o Planejamento Urbano das Cidades de Porte Médio e Pequeno: Proposições Metodológicas para Estudo e sua Aplicação à Cidade de Londrina/PR. 1994. São Paulo: Tese (Doutorado) Programa de Pós-Graduação em Geografia Física, Faculdade de Filosofia, Letras e Ciências Humanas, Universidade de São Paulo, São Paulo, 1994.

MENDONÇA, F. Clima e Planejamento Urbano em Londrina: preposição metodológica e de intervenção urbana a partir do estudo do campo termo-higrométrico. In: MONTEIRO C. A. de F., MENDONÇA, F. Clima Urbano. São Paulo: Contexto, 2003. 192p.

MONTEIRO, C. A. de F. Teoria e Clima Urbano. São Paulo: USP - Instituto de Geografia. Série teses e monografias $\mathrm{n}^{\circ} 25.1976$.

MONTEIRO, C. A. de F. Adentrar a Cidade Para Tomar-lhe a Temperatura, Geosul, Revista do Departamento de Geociências-cch, n 9, ano V, Primeiro Semestre de 1990.

NIMER, E. Climatologia do Brasil. 2. ed. Rio de Janeiro: IBGE, 1989. 419 p.

OKE, T. R. Boundary Layer Climates. London: Methuem \& Ltd. A. Halsted Press Book, John Wiley \& Sons, New York, 1978, 372p.

SETTE, D. M. O clima urbano de Rondonópolis - MT. 1996. Dissertação (Mestrado) - Programa de Pós-Graduação em Geografia Física, Faculdade de Filosofia, Letras e Ciências Humanas, Universidade de São Paulo, São Paulo, 1996.

VIANA, S. S. M. Caracterização do Clima Urbano em Teodoro Sampaio/SP. 2006. 190 f. São Paulo: Dissertação (Mestrado em Geografia), Programa de Pós-Graduação em Geografia, Faculdade de Ciências e Tecnologia, UNESP, Presidente Prudente, 2006.

Trabalho enviado em setembro de 2009

Trabalho aceito em dezembro de 2009

Mercator - volume 8, número 17, 2009: set./dez. 